\title{
Diversity Analysis of an Extremely Acidic Soil in a Layer of Coal Mine Detected the Occurrence of Rare Actinobacteria
}

\author{
Megga Ratnasari PIKOLI ${ }^{1, *}$, Irawan SUGORO ${ }^{2}$ and Suharti $^{3}$ \\ ${ }^{I}$ Department of Biology, Faculty of Science and Technology, Universitas Islam Negeri Syarif \\ Hidayatullah Jakarta, Ciputat, Tangerang Selatan, Indonesia \\ ${ }^{2}$ Center for Application of Technology of Isotope and Radiation, Badan Tenaga Nuklir Nasional, \\ Jakarta Selatan, Indonesia \\ ${ }^{3}$ Department of Chemistry, Faculty of Science and Computation, Universitas Pertamina, \\ Simprug, Jakarta Selatan, Indonesia
}

("Corresponding author's e-mail: meggapikoli@uinjkt.ac.id, meggapikoli@yahoo.com)

Received: 7 September 2017, Revised: 11 September 2018, Accepted: 29 October 2018

\begin{abstract}
Studies that explore the diversity of microorganisms in unusual (extreme) environments have become more common. Our research aims to predict the diversity of bacteria that inhabit an extreme environment, a coal mine's soil with $\mathrm{pH}$ of 2.93. Soil samples were collected from the soil at a depth of 12 meters from the surface, which is a clay layer adjacent to a coal seam in Tanjung Enim, South Sumatera, Indonesia. A culture-independent method, the polymerase chain reaction based denaturing gradient gel electrophoresis, was used to amplify the 16S rRNA gene to detect the viable-but-unculturable bacteria. Results showed that some OTUs that have never been found in the coal environment and which have phylogenetic relationships to the rare actinobacteria Actinomadura, Actinoallomurus, Actinospica, Streptacidiphilus, Aciditerrimonas, and Ferrimicrobium. Accordingly, the highly acidic soil in the coal mine is a source of rare actinobacteria that can be explored further to obtain bioactive compounds for the benefit of biotechnology.
\end{abstract}

Keywords: Acidic soil, Actinobacteria, Biodiversity, Clay soil, Coal mine

\section{Introduction}

Studies on microbial diversity in soil are subject to many interests, since each type contains distinctive diversity which depends on its specific physical and chemical properties. Due to the completeness of the biotic and abiotic factors provided therein, a soil type is well known as a haven for a diversity of microorganisms. It was predicted that soil diversity exceeds that of aquatic environments and is a great resource for the biotechnological exploration of novel organisms, products, and processes [1,2]; approximately $20 \%$ of them appear to be endemic to certain soil [3]. Examples of products that have been explored from soil source are: lipase/esterase-, amylase-, protease-, and cellulose-producing clones [4] and cold-active enzymes ( $\beta$-galactosidases, $\alpha$-amylases and a phosphatase) [5], and chitinase for controlling fungal phytopathogen [6].

Bacteria are the most studied among the microorganisms in the soil, since they are known as microbes which face tough environmental conditions, have many roles in biogeochemical cycles, are able to adapt quickly, and have simplicity in their genome. These properties are also favorable to biotechnology, in their ease of being engineered. Prokaryotes are the most easily targeted by tools because it is assumed that they are the most abundant organisms in soil. In addition, the increasing discovery of a new bacterial species raises the question of what are likely still many unknown species out there. Therefore, the exploration of soil bacteria is still in demand. 
http://wjst.wu.ac.th

In the current study, we assessed an extremely acidic soil derived from a coal mine in order to investigate the bacterial diversity of a soil layer adjacent to a coal seam and to detect bacteria that cannot be detected by the common culture-dependent method. In this paper, we discuss the detected OTUs closely related to rare actinobacteria. Their presence is unexpected since none of them were found in a nearby coal seam, as in our previous study [7]. Rare actinobacteria are relatively difficult to isolate, culture, and maintain, due to the difficulties in maintaining and mimicking their natural environment. They have been considered as non-Streptomyces actinobacteria strains which require certain requirements to be obtained [8]. Their existence is greatly valuable because they produce new bioactive compounds different from those have ever been discovered from the Streptomyces group [8,9].

Among the soil bacteria, actinobacteria is a group whose members are considered to be rarely isolated. They are metabolically active but difficult to isolate by ordinary techniques. Actinobacteria are known as the source of novel antibiotics or other bioactive compounds, in which a single isolate may have the genetic potential to synthesize more than one secondary metabolite with many biological activities [8,10-12]. As decomposer organisms, actinobacteria use autotrophic or heterotrophic metabolism. Generally, most known actinobacteria are heterotrophic [13], but recent studies showed that some among them use autotrophic metabolism [14,15]. This convinces us of the role of actinobacteria as versatile decomposers, in which the role and capabilities can be explored further. Therefore, the detection of this group of bacteria in a specific environment is worthwhile, and some strategies to obtain them must be designed.

The rare bacteria are hard to detect by the culture-dependent method [16,17]. Cultivation needs costs of trying different commercial media and often results in high rediscovery frequency of the same species. Many types of bacteria actually exist but are not detected by the culture methods. Examination of the existence of bacteria before exploration can save costs and time. Therefore, this study used a cultureindependent approach by using denaturing gradient gel electrophoresis targeting the 16S rRNA, which has been widely used. The method has found the existence of strains that play an important role in the natural processes in various environments $[18,19]$.

\section{Materials and methods}

\section{Site description}

The soil sample was a composite of 5 bulks of soil. They were collected randomly within $10 \mathrm{~cm}-$ thickness of top soil. The site is a coal mine located in Muara Tigo Besar Utara, managed by the Bukit Asam Company in South Sumatera, Indonesia. The sample was taken from a coal lower floor which was located below a coal seam at the coordinates of S 034'29.4", E10345'11.8". Analysis of soil properties was conducted at the Center for Soil Research, Bogor, Indonesia. The soil sample was transported to the laboratory in the form of bulk to maintain microconditions inside. Mixing of the bulks and analysis of properties were carried out in the laboratory at room temperature $\left(28-29{ }^{\circ} \mathrm{C}\right)$.

\section{DNA extraction and purification}

The DNA extraction was performed in three different modifications: direct, filtration, and blending, modified from the protocol of DNA extraction from soil [20]. In the direct method, DNA extraction was applied directly to the soil sample, while in the filtration and blending methods, DNA extractions were carried out indirectly, which were applied after the cells were harvested from the original sample. In the filtration method, $1 \mathrm{~g}$ soil was washed with $100 \mathrm{ml}$ of washing solution. The washing solution comprised three kinds: saline solution, $\mathrm{H}_{2} \mathrm{SO}_{4} \mathrm{pH} 3$ in saline solution, and $\mathrm{H}_{2} \mathrm{SO}_{4} \mathrm{pH} 2$ in saline solution, respectively. At the end of each washing, collected supernatant was filtered by vacuum filter with 0.22 $\mu \mathrm{m}$ of pore-size to obtain a cell pellet. In the blending method, washing solution was the same as the filtration method, but the soil sample was washed whilst being blended by a high-speed blender for 1 minute in every step of washing. Then, the collected cells from the filtration and the blending method were subjected to DNA extraction, as per the direct method. The DNA extract was purified by polyvinylpolypyrrolidone in a spin column and eluted with $30 \mu \mathrm{l}$ of $10 \mathrm{mM}$ Tris- $\mathrm{HCl}$ buffer $\mathrm{pH} 8$ to harvest cleaner final extract. 


\section{PCR-DGGE}

Partial sequence of $16 \mathrm{~S}$ rRNA gene (408 bp) was amplified using the primer set: Com1-F (5'-CAG CGC CAG GGT AAT AC-3', with GC-clamp 5'-CGC CCG CCG CGC GCG GCG GGC CGG GGG GGG GGG GGG CAC), and Com2-R (5'-CGG TCA ATT CCT TTG AGT TT-3') [21]. The reaction mixture $(50 \mu \mathrm{L})$ contained $1.0 \mu \mathrm{L}$ of $10 \mathrm{mM}$ each primer, $5.0 \mu$ Lof $10 \times$ Taq buffer, $1.0 \mu \mathrm{L}$ of $10 \mathrm{uM}$ deoxyribonucleotide triphosphate mixture, $4.0 \mu \mathrm{L}$ of total DNA, and $0.25 \mu \mathrm{L}$ of $5 \mathrm{U} / \mu \mathrm{l}$ Taq DNA polymerase. DNA fragments were amplified as follows: initial denaturation at $95{ }^{\circ} \mathrm{C}$ for $5 \mathrm{~min}$, followed by 30 cycles consisting of denaturation at $95{ }^{\circ} \mathrm{C}$ for $1 \mathrm{~min}$, annealing at $51^{\circ} \mathrm{C}$ for $1 \mathrm{~min}$, extension at 72 ${ }^{\circ} \mathrm{C}$ for $1 \mathrm{~min}$, and a $10 \mathrm{~min}$ final extension step at $72{ }^{\circ} \mathrm{C}$. DGGE was performed with a Dcode Universal Mutation Detection System (Bio-Rad) containing TAE buffer. PCR products were loaded onto a 7\% polyacrylamide gel containing 30 to $80 \%$ denaturant gradient of urea and formamide solution. Each sample $(40 \mu \mathrm{L})$ consisted of three PCR products, and $8 \mu \mathrm{L}$ of $5 \times$ loading dye were loaded onto gels and then run for $12 \mathrm{~h}$ at $60{ }^{\circ} \mathrm{C}$ under $70 \mathrm{~V}$. After the runs, the gel was stained with silver staining and scanned. DGGE bands were cut, eluted, and reamplified by using the primers previously described but without a GC-clamp. In detail, each of the distinct DGGE bands was cut, then put into a microtube containing 100 $\mu \mathrm{l}$ of $10 \mathrm{mM}$ Tris-HCl pH 8.0 solution and incubated overnight at room temperature to elute DNA from the gel. The eluted DNA was used as a template for reamplification. PCR products were then purified, and their sequencing was ordered commercially from Macrogen Inc., South Korea.

\section{Data analysis}

Scanned DGGE gel was analyzed for band intensity using ImageJ [22]. Band profiles were quantified to determine a total number of bands (S), peak surface of each band (ni), and a sum of all the peak surfaces of all bands (N) [23]. This information was used to calculate the community biodiversity using three indices: the Shannon index $(\mathrm{H})$ calculated with the formula $\mathrm{H}=-\Sigma(\mathrm{ni} / \mathrm{N}) \ln (\mathrm{ni} / \mathrm{N})$; the dominance index (c) calculated with the formula $\mathrm{c}=\Sigma(\mathrm{ni} / \mathrm{N})^{2}$; and (iii) the evenness index (e) calculated with the formula $\mathrm{e}=\mathrm{H} / \mathrm{lnS}$. AS (acidic soil) was used as the code of DGGE band, followed by the number in its lane (community). The PCR chimeras were scanned by DECIPHER's Find Chimeras [24]. Sequences were compared to the sequences in the National Center for Biotechnology Information (NCBI) data bank using Blast (https://blast.ncbi.nlm.nih.gov/). Alignment of DNA sequences was conducted by the Muscle program, and a phylogenetic tree was constructed in MEGA6 [25] with 1000 bootstrap replicates. The tree was inferred by using the Maximum Likelihood method based on the Kimura 2parameter model (Kimura 1980) with Gamma distribution to model evolutionary rate differences among sites. All positions with less than $95 \%$ site coverage were deleted. The tree was then visualized using TreeGraph 2 [26]. All the 16S rRNA gene sequence data reported in this paper were deposited in GenBank under accession numbers KY366422-KY366442.

\section{Results and discussion}

\section{Soil properties}

The soil is confirmed as an extremely acidic clay soil with $42 \%$ clay proportion and pH 2.93 (Table 1). In the point of $\mathrm{C} / \mathrm{N}$ ratio and cations, the soil was at a moderate level that is suitable to support plant growth. Therefore, the soil was thought rich in microorganisms living in it. However, the iron and aluminum content were very high, in the amounts of 32,600 and $64,800 \mathrm{ppm}$, respectively, which are supposed to be toxic to plants. Therefore, the acidity of soil was assumed due to the high content of iron and aluminum.

Study on microorganisms in extreme environments are of concern in microbial ecology and biodiversity. It is driven by curiosity about the presence of microorganisms in an unusual environment, the environmental factors that influence it, and the need to obtain microorganisms different from those already obtained. The microbial community structure in the extreme sites is primarily influenced by environment properties, such as $\mathrm{pH}[27,28]$. The existence of microorganisms may show an interesting source of novel enzymes or genes, and enrich the knowledge of mechanisms involved in adaptation to extreme conditions $[27,29,30]$. 
http://wjst.wu.ac.th

Table 1 Soil properties.

\begin{tabular}{ll}
\hline Sand proportion & $29 \%$ \\
Silt proportion & $29 \%$ \\
Clay proportion & $42 \%$ \\
Total pore & $50.3 \% \mathrm{vol}$ \\
Bulk density & $1.12 \mathrm{~g} \mathrm{cc}^{-1}$ \\
Particle density & $2.26 \mathrm{~g} \mathrm{cc}^{-1}$ \\
Electrical conductivity & $0.532 \mathrm{dS} \mathrm{m}^{-1}$ \\
Salinity & $255 \mathrm{mg} \mathrm{L}^{-1}$ \\
Water content & $9.8 \%$ \\
pH in CaCl & 2.93 \\
Organic $\mathrm{C}$ & $3.07 \%$ \\
Organic N & $0.23 \%$ \\
C/N Ratio & 13.35 \\
Cation exchange & $13.92 \mathrm{cmol}_{(+)} \mathrm{kg}^{-1}$ \\
Free cation & $77 \%$ \\
Total P & $0.15 \%$ \\
Total $\mathrm{K}$ & $0.23 \%$ \\
Total Ca & $0.11 \%$ \\
Total $\mathrm{Mg}$ & $0.30 \%$ \\
Total Na & $0.04 \%$ \\
Total S & $0.18 \%$ \\
Total Fe & $3.26 \%$ \\
Total $\mathrm{Al}$ & $6.48 \%$ \\
\hline
\end{tabular}

\section{Bacterial diversity}

The band profile resulting in DGGE gel showed a similar profile among DNA obtained from the three modification methods of DNA extraction (Figure 1). It resulted in the similar dominance of the diversity. However, the number of bands is slightly different among the three methods. Assuming that each band represented one operational taxonomical unit (OTU), the diversity indices have been calculated (Table 2).

Table 2 Diversity indices of the soil community obtained from different DNA extraction methods.

\begin{tabular}{cccc}
\hline & \multicolumn{3}{c}{ DNA extraction method } \\
\cline { 2 - 4 } Diversity indices & \multirow{2}{*}{ Direct } & \multicolumn{2}{c}{ Indirect } \\
\cline { 2 - 4 } & & 28 & Filtration \\
\hline Richness (S) & 21 & 2.52 & 2.64 \\
Shannon (H') & 2.68 & 0.78 & 0.81 \\
Evenness (e) & 0.89 & 0.13 & 0.10 \\
Dominance (c) & 0.11 & & \\
\hline
\end{tabular}

The total number of the OTUs (richness) obtained from the indirect method (filtration and blending) was a lot more than from the direct method. OTUs of AS4, AS5, AS12, AS13, AS25, AS28, AS29, and AS30 not detected from the direct method were detected from either the filtration or the blending methods. In the meantime, the direct method of DNA extraction obtained members of the majority, i.e., 
http://wjst.wu.ac.th

OTUs with higher abundance, by having thicker bands on the DGGE gel, which were AS1, AS2, AS7, AS8, AS8b, and AS11 (data not shown). This compensated for their diversity, so the Shannon index of those resulting from the three methods did not differ significantly. The individual abundance of the other members from the direct method, on average, looked equal, resulting in a higher evenness in comparison with the two indirect methods.

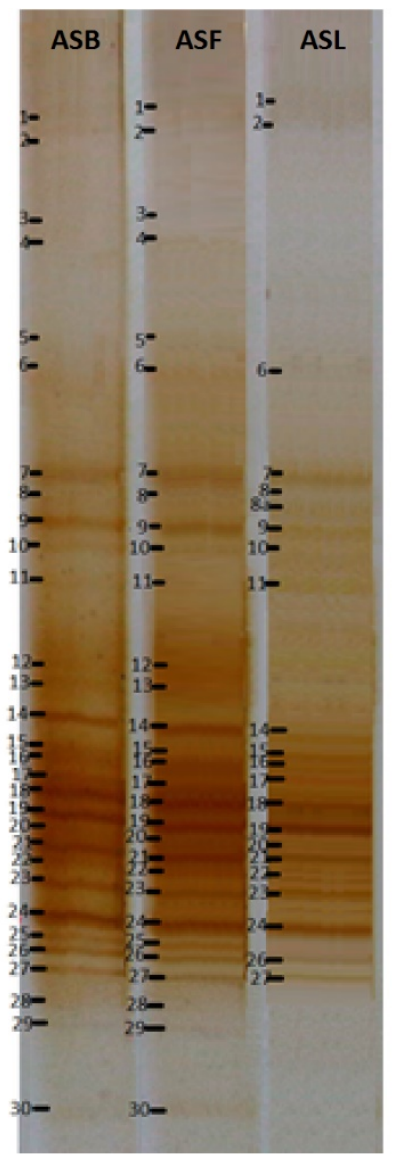

Figure 1 DGGE band profile of 16S rRNA gene extracted by different methods. ASB = blending method; $\mathrm{ASF}=$ filtration method; ASL = direct method. The same number means the same band.

The attachment of bacteria to the clay material is facilitated by bacterial extracellular polymeric substances (EPS) [31]. The cell wall of Actinomadura madura, a species of Actinobacteria, contains poly(galactosyl-1 $\rightarrow$-glycerol phosphate) and poly-(3-O-methylgalactosyl-1 $\rightarrow 2$-glycerol phosphate) [32]. It has been known that the mine soil in this study contains a high percentage of iron (Table 1). The adhesion of bacteria, such as acidophilic iron-oxidizer Ferrimicrobium acidiphilum, in a biofilm to minerals is mediated by gel-like EPS produced outside the cell wall (peptidoglycan layer) [33].

In addition, the amount of cell adsorption increases at $\mathrm{pH} 2.0$ - 3.0 because of the widespread electrostatic nature (surface charge) both on the bacterial cell surface and mineral surfaces [31,34]. The composition of EPS in an iron oxidizing-bacteria results in a net positive charge of cells. Therefore, the positive-charged bacteria attach to the negative-charged mineral surface in an acidic environment due to the electrostatic forces [33]. 
http://wjst.wu.ac.th

The bacterial cell attachment on the clay particles can also be explained by the high cation content. The mine soil in this study has a high content of cations (Table 1), which can mediate cell adhesion of soil bacteria on clay particles. Clay particles have a negative charge on their surface. In Gram-positive bacteria, the negative charge on their surface comes from lipoteichoic acid, whereas in Gram-negative bacteria, the negative charge is derived from the lipopolysaccharide. Repulsion between clay particles and bacterial cells that are equally negatively charged do not occur, since cations in the soil bind to the negative charges, either on the surface of the clay or in the bacterial cells, so this mediates attachment of the cells on the clay particles [35].

Table 3 The sequenced OTUs and their similarity to GenBank.

\begin{tabular}{|c|c|c|c|c|}
\hline $\begin{array}{c}\text { Band } \\
(\text { OTU) }\end{array}$ & Closest related taxa in bank & $\begin{array}{c}\text { Similarity } \\
(\%)\end{array}$ & Phylum & $\begin{array}{c}\text { Class of the phylum } \\
\text { Actinobacteria }\end{array}$ \\
\hline AS4 & Burkholderia pedi type strain LMG 29323T & 94 & Proteobacteria & \\
\hline AS6 & Conexibacter arvalis strain KV-962 & 99 & Actinobacteria & Thermoleophilia \\
\hline AS9 & Acidibacter ferrireducens strain MCF85 & 99 & Proteobacteria & \\
\hline AS12 & Ferrimicrobium acidiphilum strain T23 & 91 & Actinobacteria & Acidimicrobiia \\
\hline AS13 & Streptomyces sp. CPB1-1 & 94 & Actinobacteria & Actinobacteria \\
\hline AS14 & Ferrimicrobium acidiphilum strain T23 & 95 & Actinobacteria & Acidimicrobiia \\
\hline AS 15 & Streptomyces aegyptia strain NEAE & 96 & Actinobacteria & Actinobacteria \\
\hline AS16 & Streptomyces luteireticuli NRRL B-12435 & 93 & Actinobacteria & Actinobacteria \\
\hline AS17 & Streptomyces aegyptia NEAE 102 & 95 & Actinobacteria & Actinobacteria \\
\hline AS18 & Aciditerrimonas ferrireducens IC-180 & 95 & Actinobacteria & Acidimicrobiia \\
\hline AS19 & Streptacidiphilus neutrinimicus NBRC 100921 & 99 & Actinobacteria & Actinobacteria \\
\hline AS20 & Streptacidiphilus neutrinimicus NBRC 100921 & 99 & Actinobacteria & Actinobacteria \\
\hline AS21 & Actinospica sp. 45151 & 99 & Actinobacteria & Actinobacteria \\
\hline AS22 & Streptacidiphilus neutrinimicus NBRC 100921 & 100 & Actinobacteria & Actinobacteria \\
\hline AS23 & Streptomyces echinoruber X-14077 & 92 & Actinobacteria & Actinobacteria \\
\hline AS24 & Thauera humireducens SgZ-1 & 89 & Proteobacteria & \\
\hline AS25 & Actinospica robiniae GE134769 & 98 & Actinobacteria & Actinobacteria \\
\hline AS26 & Actinoallomurus purpureus TTN02-30 & 99 & Actinobacteria & Actinobacteria \\
\hline AS28 & Actinomadura amylolytica YIM 77502 & 94 & Actinobacteria & Actinobacteria \\
\hline AS29 & Rubrobacter taiwanensis LS-293 & 96 & Actinobacteria & Rubrobacteria \\
\hline AS30 & Sphaerobacter thermophilus DSM 20745 & 97 & Chloroflexi & \\
\hline
\end{tabular}

Considering the strong attachment of bacterial cells to the soil particles and minerals, as mentioned above, DNA extraction from the acidic clay soil really needs prior treatment to separate cells from the soil matrix. Separation of cells from clay particles is very important to have complete diversity. The type of DNA extraction method affects the diversity and community structure in an environmental sample, as visualized by PCR-DGGE [36,37]. Increasing vigor in DNA extraction is needed as the soil humic acid and clay content increases, notwithstanding a consequential decrease in the average DNA fragment size. Bacterial cells attached predominantly to small particles $(<2 \mu \mathrm{m})$ and, hence, remaining unattenuated during transport, would rapidly be transported across the surface in runoff generated by saturation-excess conditions $[38,39]$. The size of bacteria and clay minerals which are in the same order become the reason for the difficulty in separating the cells from clay minerals, and the amount of cell adsorption increases with $\mathrm{pH}$ from 2.0 to 3.0 due to the extent of electrostatic properties or surface charges of both the bacterial and mineral surfaces [34,40]. In this study, we applied sulfuric acid as the washing solution, in the $\mathrm{pH}$ range resembling the soil samples, since it was assumed that the cell runoff would be a lot more due to the suitability of the washing solution to their natural environment. 
http://wjst.wu.ac.th

The level of success in obtaining bacterial cells meant the Shannon index of the DNA resulting from the direct extraction method was slightly higher than those from the indirect method (Table 2). It was expected that members of the minority had a tight association with clay particles lost along with clay particles during the extraction process. Meanwhile, the indirect DNA extraction methods, which were preceded by physical separation of the cells, recruited members of the minority, which were characterized by thinner bands (Figure 1). These results were used to compare the three methods and indicated which method could obtain a higher diversity and see the whole community more completely.

Not all DGGE bands were reamplified successfully. The known sequences had low to high similarity to species sequences in GenBank (Table 3). Most of them (about $81 \%$ ) were of phylum Actinobacteria. OTUs of AS4 and AS30 were of the phyla of Proteobacteria and Chloroflexi, respectively, as well as OTUs of AS12, AS13, AS25, AS28, and AS29, which were of phylum Actinobacteria, were not detected by the direct method. This revealed the advantage of the indirect extraction methods, which succeeded in extracting much more of the uncultured bacteria than the direct method. Most of the class (71 \%) within the phylum Actinobacteria are of class Actinobacteria, whereas the rest are of the classes Thermophilia, Acidimicrobiia and Rubrobacteria.

Clay soil is known as broadly containing organisms closely associated with the clay matrix. Within the inner part, the majority of bacteria (about $72 \%$ of total bacteria and $87 \%$ of viable heterotrophic bacteria) were found located in the microaggregate fractions and in the dispersible clay fraction; they were correlated with the level of organic carbon and clay contents [41]. This showed that the extremely acidic clay soil is a suitable habitat for the abundant acidophilic bacteria. Some of the bacteria detected in the current research are related to the acidophilic bacteria found in very acidic environments. Ferrimicrobium acidiphilum T23, which is related to AS12 and AS14, was found in an extremely acidic mine site [42]. Aciditerrimonas ferrireducens IC-180, which is related to AS18, is an acidophilic actinobacteria and was found in an acidic solfataric field [43]. Acidibacter ferrireducens MCF85, which is related to AS9, is an acidophilic gammaproteobacteria and was isolated from a pit lake at an abandoned metal mine [44]. Actinospica robiniae GE134769 and Actinospica sp. A1SCA6, which are related to AS21 and AS25, are acidophilic bacteria and were isolated from forest soil $[45,46]$.

The proportion of OTUs in the acidic soil community showed three OTUs which had the highest proportion (Figure 2). The most dominant OTU, AS7, cannot be identified, because it failed in the PCR amplification and the subsequent processes. Meanwhile, the other top OTUs, AS9 (close to Acidibacter ferrireducens) and AS24 (related to Thauera humireducens), are of the phylum Proteobacteria. This revealed that the Proteobacteria are members who have high individual abundance. Nevertheless, from the point of the number of species, thus the richness, the phylum Actinobacteria are still the most widely detected, despite the abundance of each individual being less than $9 \%$. 
http://wjst.wu.ac.th

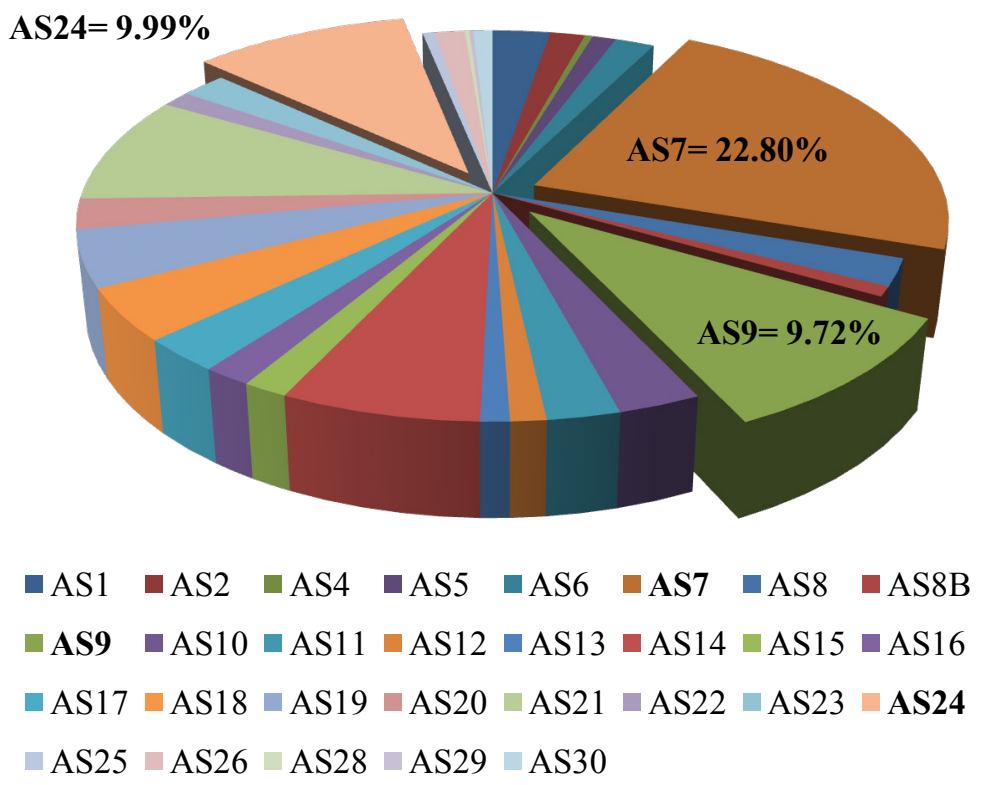

Figure 2 Proportion of the OTUs within the soil community. The three OTUs with the highest values are shown.

The close relationship of some OTUs from this study to the phylum Actinobacteria was expected from their existence in an acid soil sample. Considering their presence in the soil sample with $\mathrm{pH}$ of 2.3, it is confirmed that they constitute acidophiles with an optimal pH at, or below, 3 - 4 [47]. For example, the genera Streptomyces and Streptacidiphilus accounted for the majority (57.8\%) of 23 OTUs in a red soil in China, with pH between 2.6 and 6.6 [9]. Streptomyces and Streptacidiphilus also comprised 63.6 $\%$ of 33 Actinobacteria OTUs isolated from an acidic soil in Malaysia, with pH 4.15 to 5.89 [48]. Meanwhile, regarding the proportion of Actinobateria OTUs obtained from the current research in extremely acidic soil from a coal mine, the proportion of Actinobacteria OTUs having a close relationship to Streptomyces and Streptacidiphilus was $47.1 \%$ of the whole detected phylum Actinobacteria.

\section{Phylogenetic relationships}

The maximum parsimony analysis of the dataset comprised 67 taxa, including 21 OTUs from DGGE and Brachyspira ibaraki (AB079583), as the outgroup resulted in one tree (Figure 3). Seventeen OTUs belong to the phylum Actinobacteria. AS26 is closely related to Actinoallomurus with $98 \%$ bootstrap, and along with AS28 belongs to order Streptosporangiales in the class Actinobacteria with 53 $\%$ bootstrap. AS15, AS17, and AS13 are clustered, and with AS23, are related to order Streptomycetales in class Actinobacteria with low support. AS16, the OTU which has similarity to Streptomyces luteireticuli, is located within the cluster class of Acidimicrobiia along with AS18, AS12, and AS14, instead of the cluster in the class of Actinobacteria. AS21 and AS25 are clustered within the order Catenulisporales with $99 \%$ bootstrap. AS19, AS20, and AS22 are closely related to Streptacidiphilus neutrinimicus with $53 \%$ bootstrap. AS6 belongs to species Conexibacter arvalis which is supported by $99 \%$ bootstrap. It is the only member of the class Thermoleophilia in the phylum Actinobacteria that forms a cluster with the phylum Proteobacteria, though with a low support of bootstrap. Within the phylum of Proteobacteria, AS9 and AS4 are supported by high bootstrap values to their references; AS9 is closely related to Acidibacter ferrireducens with $99 \%$ bootstrap, and AS4 to Burkholderia pedi and B. ptereochthonis with $93 \%$ bootstrap. The relationship of AS29 to Rubrobacter taiwanensis, the member of class Rubrobacteria in the phylum Actinobacteria, does not have any support. AS30 is closely 
http://wjst.wu.ac.th

(bootstrap $100 \%$ ) related to Sphaerobacter thermophilus, the only member of the phylum Chloroflexi in this soil community.

A higher proportion of Actinobacteria (52.9 \%) OTUs have close relationships to rare Actinobacteria species. Rare actinobacteria refers to groups containing members of non-streptomyces species [8]. AS26 and AS28, which belong to order Streptosporangiales in the class Actinobacteria with $53 \%$ bootstrap, are OTUs those have close relationship to Actinoallomurus purpureus and Actinomadura amylolytica. AS26 has a high similarity (99\%) with Actinoallomurus purpureus TTN02-30, which is the type strain of the rare species that has only been published by Tamura et al. so far [49]. This OTU is also close to the other Actinoallomurus strains that are supported by bootstrap $98 \%$; these are Actinoallomurus sp. 645 122, Actinoallomurus sp. 645 152, and Actinoallomurus sp. 645150 from acid soils in Malaysia [48], as well as Actinoallomurus sp. FXJ1.503 from a red soil in China [9]. Actinomadura amylolytica YIM 77502, which is located within a clade with AS26 and AS28, is a rare actinobacterium isolated from geothermally heated soil located in China but is not related to an acidic environment [50].

AS21 and AS25, which belong to order Catenulisporales in the class Actinobacteria with 99\% bootstrap, are OTUs adjacent to Actinospica robiniae GE134769, which is also a type strain of the novel genus Actinospica, a member of Actinospicaceae fam. nov. [45]. The strain was found to be obligate acidophiles ( $\mathrm{pH}$ range 4.2 - 6.2). They are also in a clade with Actinospica sp. A1SCA6 (Actinospica durhamensis sp. nov.) which was isolated from an acidic spruce soil in England [46]. This rare and unusual actinomycete is also adjacent to Actinospica sp. Gamma-22 (Actinomycetales bacterium Gamma22), which produces a new chrolactomycin [51]. 


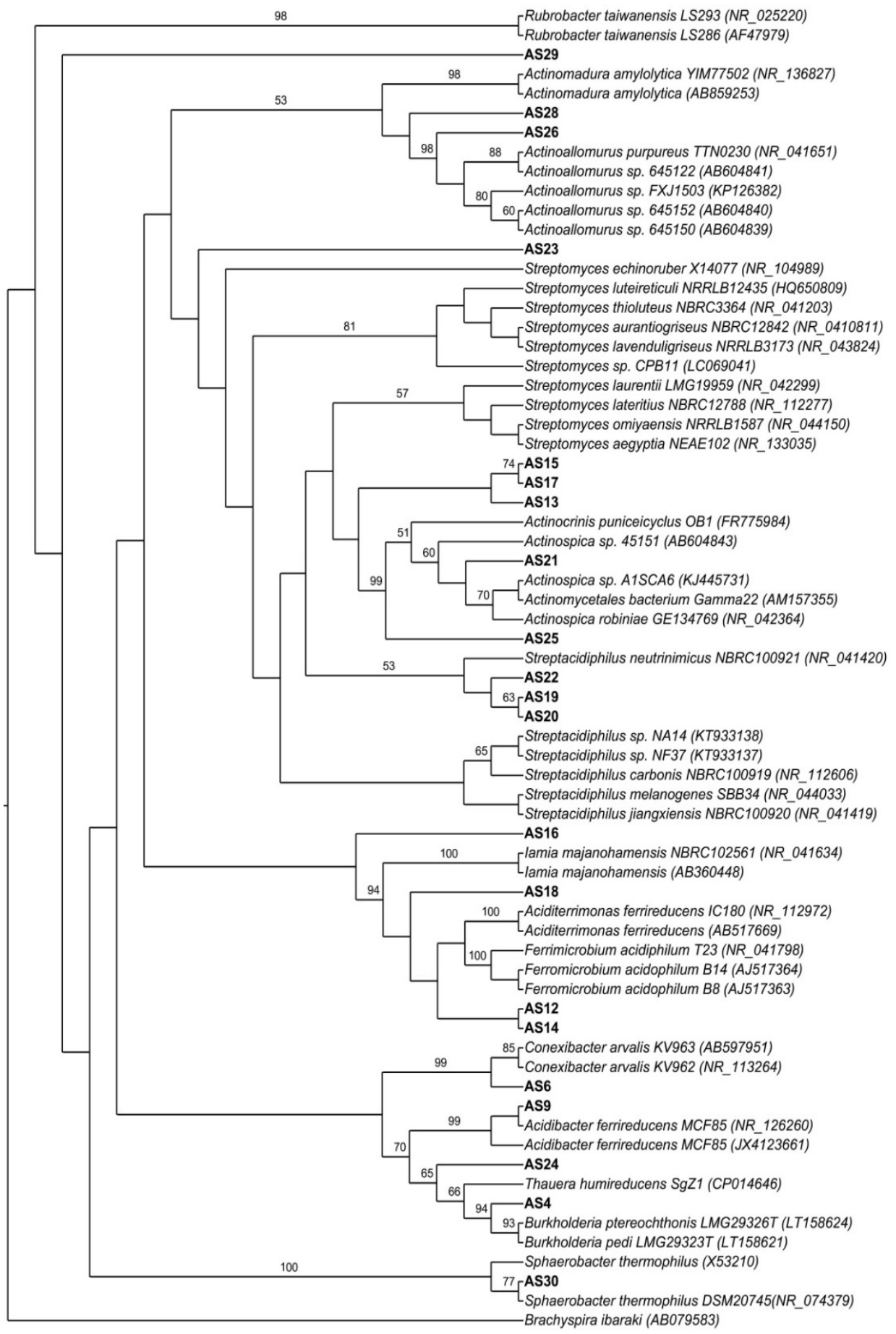

Figure 3 Phylogenetic tree of the 21 OTUs and reference sequences based on partial 16S rDNA gene amplification. Numbers on branches are confidence limits that were estimated from 1000 replicates of bootstrap. Values greater than $50 \%$ are shown. Brachyspira ibaraki (AB079583) is used as the outgroup. Asterisks mark those showing topology consistency in other algorithms (Neighbor-joining and Maximum Parsimony). 
http://wjst.wu.ac.th

AS19, AS20, and AS22 are OTUs that have a close relationship (53\% bootstrap) to the actinobacteria Streptacidiphilus neutrinimicus NBRC 100921, which is also a type strain. Acidic environments are apparently selected by members of genus Streptacidiphilus, which are obligate acidophiles [52]. This genus has been also found as rare actinobacteria in mangrove swamps, which are suggested to have valuable sources of potential metabolites [8].

AS18, AS12, and AS14 are OTUs within the cluster class of Acidimicrobiia. The genera Ferrimicrobium and Aciditerrimonas within this cluster are associated with the acidic environment resulting from the redox processes of iron compounds. Ferrimicrobium acidiphilum T23 in this cluster is an iron-oxidizing, extremely acidophilic actinobacteria [42], whereas Aciditerrimonas ferrireducens IC180 is an iron-reducing thermoacidophilic actinobacteria [43]. The mineralogical properties found in the soil sample, especially the high iron content (3.26\%) (Table 1), support physiological properties of the bacteria. Autotrophic growth of Aciditerrimonas ferrireducens occurs via $\mathrm{H}_{2}$ oxidation coupled to $\mathrm{Fe}^{3+}$ reduction anaerobically, whereas heterotrophic growth occurs via oxidation of organic carbon coupled to either $\mathrm{O}_{2}$ or $\mathrm{Fe}^{3+}$ at optimum pH 3.0 [53]. AS9 close to Acidibacter ferrireducens MCF85, is also an ironreducing bacteria, but from the phylum Proteobacteria. Considering the high proportion (9.72\%) of AS9 (Figure 2), it is expected to have competition with the iron-reducing actinobacteria close to Aciditerrimonas ferrireducens. The ecophysiological relationship of the presumptive bacteria to the ironrich soil sample is also shown by the presence of the FEAC_2323 gene in Ferrimicrobium acidiphilum DSM 19497 strain T23. The gene encodes the ferredoxin protein, whose molecules function as an iron ion binding protein, a property needed by iron oxidizers. Data from UniProt.org shows that this protein resembles $4 \mathrm{Fe}-4 \mathrm{~S}$ ferredoxin, which is also owned by more than 70 members of Acidimicrobiaceae [54].

Some of the actinobacteria OTUs, which are AS12 (related to Ferrimicrobium acidiphilum), AS13, AS25 (related to Actinospica robiniae), AS28 (related to Actinomadura amylolytica), and AS29 (related to Rubrobacter taiwanensis), were undetectable from the direct method of DNA extraction. They were detected in soil samples through cell isolation by filtration or blending, which indicates they have a strong bond with clay particles, which is associated with EPS, charge, or cell surface appendages, as discussed above. Thus, the indirect DNA extraction methods are highly valuable, in that they are proven to be able to obtain bacteria that have a tight association with soil particles. These bacteria could include many types of rare actinobacteria. Furthermore, the OTUs are found to belong to groups that have a low individual abundance (less than $9 \%$ ), so it can be said that the indirect methods also help obtain members of the minority communities, which are usually difficult to detect because they are covered by the majority. Therefore, this work has proven that acidic clay soil derived from a coal mine is a biodiversity resource of acid tolerant or even acidophilic bacteria, especially rare actinobacteria species.

\section{Conclusions}

The bacterial diversity in the extremely acidic soil in the coal mine in this study was dominated by Actinobacteria which were related to acidophilic traits. There was slight difference between those obtained from the direct and indirect method of DNA extraction. The indirect methods produced more minority members and OTUs of the group of bacteria that were not detected by the direct method. The high dominance of rare actinobacteria presents a great opportunity to harvest potential actinobacteria in this type of soil.

\section{Acknowledgements}

Technical assistance in sampling of soil by Ir. Eko Pujiantoro (Manager Assistant of Geology) and his staff from the PT. Bukit Asam Company was greatly appreciated. We also thank Prof. Akhmaloka, Dr. Pingkan Aditiawati, and Dr. Dea Indriani Astuti, from Institut Teknologi Bandung, Indonesia, for their support of part of this work. 
http://wjst.wu.ac.th

\section{References}

[1] V Torsvik and L Øvreås. Microbial diversity and function in soil: From genes to ecosystems. Curr. Opin. Microbiol. 2002; 5, 240-5.

[2] D Cowan, Q Meyer, W Stafford, S Muyanga, R Cameron and P Wittwer. Metagenomic gene discovery: Past, present and future. Trends Biotechnol. 2005; 23, 321-9.

[3] PD Schloss and J Handelsman. Toward a census of bacteria in soil. PLoS Comput. Biol. 2006; 2, 786-93.

[4] R Berlemont, D Pipers, M Delsaute, F Angiono, G Feller, M Galleni and P Power. Exploring the Antarctic soil metagenome as a source of novel cold-adapted enzymes and genetic mobile elements. Rev. Argent. Microbiol. 2011; 43, 94-103.

[5] JK Vester, MA Glaring and P Stougaard. Discovery of novel enzymes with industrial potential from a cold and alkaline environment by a combination of functional metagenomics and culturing. Microb. Cell Fact. 2014; 13, 72.

[6] P Shrivastava, R Kumar and MS Yandigeri. In vitro biocontrol activity of halotolerant Streptomyces aureofaciens K20: A potent antagonist against Macrophomina phaseolina (Tassi) Goid, Saudi. J. Biol. Sci. 2015; 24, 192-9.

[7] MR Pikoli, P Aditiawati, DI Astuti and Akhmaloka. Bacterial diversity in subbituminous coal and soil from coal mine of South Sumatra, Indonesia. Int. J. Integr. Biol. 2013; 14, 96-103.

[8] AS Azman, I Othman, SS Velu, KG Chan and LH Lee. Mangrove rare actinobacteria: Taxonomy, natural compound, and discovery of bioactivity. Front. Microbiol. 2015; 6, 1-15.

[9] X Guo, N Liu, X Li, Y Ding, F Shang, Y Gao, J Ruan and Y Huang. Red soils harbor diverse culturable actinomycetes that are promising sources of novel secondary metabolites. Appl. Environ. Microbiol. 2015; 81, 3086-103.

[10] S Naorungrote and W Chunglok. Actinomycetes producing anti-methicillin resistant Staphylococcus aureus from soil samples in Nakhon Si Thammarat. Walailak J. Sci. Tech. 2011; 8, 131-8.

[11] DB Xu, WW Ye, Y Han, ZX Deng and K Hong.Natural products from mangrove actinomycetes. Mar. Drugs. 2014; 12, 2590-613.

[12] L Katz and RH Baltz. Natural product discovery: past, present, and future. J. Ind. Microbiol. Biotechnol. 2016; 43, 155-76.

[13] A Chroňáková, V Krištůfek, M Tichý and D Elhottová. Biodiversity of streptomycetes isolated from a succession sequence at a post-mining site and their evidence in Miocene lacustrine sediment. Microbiol. Res. 2010; 165, 594-608.

[14] L Procópio, VM Alvarez, DA Jurelevicius, L Hansen, SJ Sørensen, JS Cardoso, M Pádula, AC Leitão, L Seldin and JD van Elsas. Insight from the draft genome of Dietzia cinnamea P4 reveals mechanisms of survival in complex tropical soil habitats and biotechnology potential. Antonie van Leeuwenhoek, Int. J. Gen. Mol. Microbiol. 2012; 101, 289-302.

[15] G Cuesta, A Soler, JL Alonso, MA Ruvira, T Lucena, DR Arahal and M Goodfellow. Pseudonocardia hispaniensis sp. nov., a novel actinomycete isolated from industrial wastewater activated sludge. Antonie Van Leeuwenhoek 2013; 103,135-42.

[16] A Shade, CS Hogan, AK Klimowicz, M Linske, PS Mcmanus and J Handelsman. Culturing captures members of the soil rare biosphere. Environ. Microbiol. 2012; 14, 2247-52.

[17] FOP Stefani, TH Bell, C Marchand, IE De La Providencia, A El Yassimi, M St-Arnaud and M Hijri. Culture-dependent and -independent methods capture different microbial community fractions in hydrocarbon-contaminated soils. PloS One 2015; 10, 1-16.

[18] VHT Pham and J Kim. Cultivation of unculturable soil bacteria. Trends Biotechnol. 2012; 30, 47584.

[19] L Cocolin, V Alessandria, P Dolci, R Gorra and K Rantsiou. Culture independent methods to assess the diversity and dynamics of microbiota during food fermentation. Int. J. Food Microbiol. 2013; 167, 29-43.

[20] J Zhou, MA Bruns and JM Tiedje. DNA recovery from soils of diverse composition. Appl. Environ. Microbiol. 1996; 62, 316-22. 
http://wjst.wu.ac.th

[21] A Schmalenberger, F Schwieger and CC Tebbe. Effect of primers hybridizing to different evolutionarily conserved regions of the small-subunit rRNA gene in PCR-based microbial community analyses and genetic profiling. Appl. Environ. Microbiol. 2001; 67, 3557-63.

[22] CA Schneider, WS Rasband and KW Eliceiri. NIH Image to ImageJ: 25 years of image analysis, Nat. Meth. 2012; 9, 671-75.

[23] N Fromin, J Hamelin, S Tarnawski, D Roesti, N Forestier, F Gillet, M Aragno and P Rossi. Minireview Statistical analysis of denaturing gel electrophoresis (DGGE) fingerprinting patterns, Environ. Microbiol. 2007; 4, 634-43.

[24] ES Wright, LS Yilmaz and DR Noguera. DECIPHER, a search-based approach to chimera identification for 16S rRNA sequences. Appl. Environ. Microbiol. 2012; 78,717-25.

[25] K Tamura, G Stecher, D Peterson, A Filipski and S Kumar. MEGA6: Molecular evolutionary genetics analysis version 6.0. Mol. Biol. Evol. 2013; 30, 2725-9.

[26] BC Stöver and KF Müller. TreeGraph 2: Combining and visualizing evidence from different phylogenetic analyses. BMC Bioinform. 2010; 11, 7.

[27] EMS Brito, HA Piñón-Castillo, R Guyoneaud, CA Caretta, JF Gutiérrez-Corona, R Duran, GE Reyna-López, GV Nevárez-Moorillón, A Fahy and M Goñi-Urriza. Bacterial biodiversity from anthropogenic extreme environments: A hyper-alkaline and hyper-saline industrial residue contaminated by chromium and iron. Appl. Microbiol. Biotechnol. 2013; 97, 369-78.

[28] J Liu, ZS Hua, LX Chen, JL Kuang, SJ Li, WS Shu and LN Huang. Correlating microbial diversity patterns with geochemistry in an extreme and heterogeneous environment of mine tailings. Appl. Environ. Microbiol. 2014; 80, 3677-86.

[29] CJ Duan and JX Feng. Mining metagenomes for novel cellulase genes. Biotechnol. Lett. 2010; 32, $1765-75$.

[30] S Pandey, S Singh, AN Yadav, L Nain and AK Saxena. Phylogenetic diversity and characterization of novel and efficient cellulase producing bacterial isolates from various extreme environments. Biosci. Biotechnol. Biochem. 2013; 77, 1474-80.

[31] Z Hong, W Chen, X Rong, P Cai, K Dai and Q Huang. The effect of extracellular polymeric substances on the adhesion of bacteria to clay minerals and goethite. Chem. Geol. 2013; 360-361, $118-25$.

[32] NV Potekhina, AS Shashkov and IB Naumova. The cell wall of Actinomadura madura contains poly(galactosyl-1C2-glycerol phosphate) and poly-(3-O-methylgalactosyl-1C2-glycerol phosphate). Microbiologiya (Moscow) 1996; 65, 522-6.

[33] M Diao, E Taran, S Mahler and AV Nguyen. A concise review of nanoscopic aspects of bioleaching bacteria-mineral interactions. Adv. Colloid Interface Sci. 2014; 212, 45-63.

[34] D Jiang, Q Huang, P Cai, X Rong and W Chen. Adsorption of Pseudomonas putida on clay minerals and iron oxide. Colloids Surfaces B Biointerfaces 2007; 54, 217-21.

[35] IL Maier and RM Pepper. Earth Environments. In: CP Maier, RM Pepper and IL Gerba (Eds.). Environmental Microbiology. Academic Press, London, 2009, p. 57-81.

[36] Ö Ínceošlu, EF Hoogwout, P Hill and JDV Elsas. Effect of DNA extraction method on the apparent microbial diversity of soil. Appl. Environ. Microbiol. 2010; 76, 3378-82.

[37] HF Santos, FL Carmo, DCA Leite, HE Jesus, PDC Maalouf, CI Almeida, AU Soriano, D Altomari, L Suhett, V Vólaro, E Valoni, M Francisco, J Vieira, R Rocha, BL Sardinha, LB Mendes, RR João, B Lacava, RF Jesus, GV Sebastian, A Pessoa, JD van Elsas, RP Rezende, DO Pires, G Duarte, CB Castro, ASI Rosado and RS Peixoto. Comparison of different protocols for the extraction of microbial DNA from reef corals. Brazilian J. Microbiol. 2012; 43, 517-27.

[38] RW Muirhead, RP Collins and PJ Bremer. Interaction of Escherichia coli and soil particles in runoff. Appl. Environ. Microbiol. 2006; 72, 3406-11.

[39] NK Dhand, JALML Toribio and RJ Whittington. Adsorption of Mycobacterium avium subsp. paratuberculosis to soil particles. Appl. Environ. Microbiol. 2009; 75, 5581-5.

[40] Z Hong, X Rong, P Cai, K Dai, W Liang, W Chen and Q Huang. Initial adhesion of Bacillus subtilis on soil minerals as related to their surface properties. Eur. J. Soil Sci. 2012; 63, 457-66.

[41] L Ranjard, F Poly, J Combrisson, A Richaume, F Gourbière, J Thioulouse and S Nazaret. 
http://wjst.wu.ac.th

Heterogeneous cell density and genetic structure of bacterial pools associated with various soil microenvironments as determined by enumeration and DNA fingerprinting approach (RISA). Microb Ecol. 2000; 39, 263-72.

[42] DB Johnson, P Bacelar-Nicolau, N Okibe, A Thomas and KB Hallberg. Ferrimicrobium acidiphilum gen. nov., sp. nov. and Ferrithrix thermotolerans gen. nov., sp. nov.: Heterotrophic, iron-oxidizing, extremely acidophilic actinobacteria. Int. J. Syst. Evol. Microbiol. 2009; 59, 1082-9.

[43] T Itoh, K Yamanoi, T Kudo, M Ohkuma and T Takashina. Aciditerrimonas ferrireducens gen. nov., sp. nov., an iron-reducing thermoacidophilic actinobacterium isolated from a solfataric field. Int. J. Syst. Evol. Microbiol. 2011; 61, 1281-5.

[44] C Falagán and DB Johnson. Acidibacter ferrireducens gen. nov., sp. nov.: An acidophilic ferric ironreducing gammaproteobacterium. Extremophiles 2014; 18, 1067-73.

[45] L Cavaletti, P Monciardini, P Schumann, M Rohde, R Bamonte, E Busti, M Sosio and S Donadio. Actinospica robiniae gen. nov., sp. nov. and Actinospica acidiphila sp. nov.: Proposal for Actinospicaceae fam. nov. and Catenulisporinae subord. nov. in the order Actinomycetales. Int. J. Syst. Evol. Microbiol. 2006; 56, 1747-53.

[46] P Golinska, L Ahmed, D Wang and M Goodfellow. Streptacidiphilus durhamensis sp. nov., isolated from a spruce forest soil. Antonie Van Leeuwenhoek 2013; 104, 199-206.

[47] AT Bull. Actinobacteria of the Extremobiosphere. In: K Horikoshi (Ed.). Extremophiles Handbook. Springer, Japan, 2011, p. 1243.

[48] H Muramatsu, R Murakami, ZH Ibrahim, K Murakami, N Shahab and K Nagai Phylogenetic diversity of acidophilic actinomycetes from Malaysia. J. Antibiot. (Tokyo) 2011; 64, 621-4.

[49] T Tamura, Y Ishida, Y Nozawa, M Otoguro and KI Suzuki. Transfer of Actinomadura spadix Nonomura and Ohara 1971 to Actinoallomurus spadix gen. nov., comb. nov., and description of Actinoallomurus amamiensis sp. nov., Actinoallomurus caesius sp. nov., Actinoallomurus coprocola sp. nov., Actinoallomurus fulvus. Int. J. Syst. Evol. Microbiol. 2009; 59, 1867-74.

[50] JY Jiao, L Liu, EM Zhou, DQ Wei, H Ming, WD Xian, CG Yuan, JM Zhong and WJ Li. Actinomadura amylolytica sp. nov. and Actinomadura cellulosilytica sp. nov., isolated from geothermally heated soil. Antonie van Leeuwenhoek, Int. J. Gen. Mol. Microbiol. 2015; 108, 75-83.

[51] M Iorio, SI Maffioli, E Gaspari, R Rossi, P Mauri, M Sosio and S Donadio. Chrolactomycins from the actinomycete actinospica. J. Nat. Prod. 2012; 75, 1991-3.

[52] SH Cho, JH Han, CN Seong and SB Kim. Phylogenetic diversity of acidophilic sporoactinobacteria isolated from various soils. J. Microbiol. 2006; 44, 600-6.

[53] W Nitschke and V Bonnefoy. Energy Acquisition in Low-pH Environments. In: R Quatrini and DB Johnson (Eds.). Acidophiles: Life in Extremely Acidic Environments. Caister Academic Press, Norfolk, UK, 2016, p. 19-48.

[54] UniProt Consortium. UniProt: The universal protein knowledgebase. Nucleic Acids Res. 2018; 46, 2699. 